\title{
The role of behavioral, autonomous, and adaptive processes in the rodent's thermoregulation
}

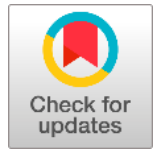

\author{
Maiko Roberto Tavares Dantas ${ }^{a, b *}$ (iD) | João Batista Freire Souza-Junior ${ }^{b}$ (iD) \\ 'Laboratory on Animal Germplasm Conservation, Universidade Federal Rural do Semi-Árido, BR 110, Km 47, 59625-900, Mossoró, RN, Brazil. \\ Laboratory of Biometeorology and Environmental Biophysics, Universidade Federal Rural do Semi-Árido, BR 110, Km 47, 59625-900, Mossoró, RN, Brazil.
}

Corresponding author: mk_ufersa@hotmail.com

\begin{abstract}
Meteorological variables are the main abiotic factors that directly influence reactions in rodent metabolism, activating the action of thermoregulatory mechanisms aimed at homeostasis and can involve several factors that work together to dissipate or conserve body heat. In this scenario, we aimed to address, synthetically, the main means that rodents have to adapt and survive faced with the thermoregulatory challenges posed by the environment in which they live. Among these processes, behavioral changes can occur in water and food intake, as well as voluntary displacement to environments offering greater thermal comfort. The autonomic processes involve innate mechanisms that act quickly to facilitate thermal exchange, such as sweating, respiratory evaporation, and changes in peripheral blood flow. Adaptation involves evolutionary processes that, in the long run, alter the morphophysiological characteristics of the epidermis and coat, in order to conserve or dissipate heat. Knowledge of the role of these processes in adaptive physiology is essential to understand how the thermal environment affects rodents and how deleterious effects are mitigated.
\end{abstract}

Keywords adaptation, climate, Rodentia, survival

\section{Introduction}

Since climate change directly affects the ecosystem, projections of the impacts of warming on small mammals, such as rodents, suggest that diurnal species may lose habitable space globally, due to thermal discomfort (Bonebrake et al 2020). Meteorological variables are the main abiotic factors that directly influence reactions in the animals' metabolism and activity time, which in turn trigger the action of thermoregulatory mechanisms aiming at homeostasis (Silva 2000; Gordon 2012; Gordon et al 2014; Bonebrake et al 2020). As survival becomes increasingly difficult because of climate change, it is becoming ever more important for mammals to use their thermoregulatory processes to exchange body heat with the environment, aiming to achieve thermal comfort (Bonebrake et al 2020).

Body temperature regulation is a process that can involve several factors that work together to dissipate or conserve heat (Figure 1). For example, behavioral changes can occur in water and food intake, as well as voluntary displacement to environments with greater thermal comfort. Autonomic processes involve innate mechanisms, such as sweating, respiratory evaporation, and changes in peripheral blood flow, that act quickly to facilitate thermal exchange. Adaptation involves evolutionary processes that, in the long run, alter the morphophysiological characteristics of the epidermis and coat, to conserve or dissipate heat (Silva 2000). As basal rodent metabolism directly depends on the climate, it is essential to understand how the thermal environment affects organisms and how they attempt to mitigate the damage caused (Rezende and Bozinovic 2019), making the animals express their characteristics efficiently.

We aimed to address, synthetically, the main means that rodents have to adapt and survive, with regard to the thermoregulatory challenges caused by the environment in which they live.

\section{Behavioral processes}

Sudden changes in temperature can cause heat stress, and usually adversely affects the immune system, which makes animals more susceptible to infection (Silva 2000). However, innate primitive behavior leads animals to choose a more comfortable thermal environment, which is essential to the efficient thermoregulatory response of mammals, including rodents, as well as for birds, and several other animal species (Gordon et al 2014).

Thermoregulatory behavior is easily observed in laboratory mice, when the rodent is allowed to move freely along a temperature gradient, they select themselves. These studies show that individual rats placed on a gradient prefer a daytime temperature of 30 to $32{ }^{\circ} \mathrm{C}$, a temperature equivalent to thermoneutrality for these animals (Gordon 2012). Thermoregulatory behavior can alter organ development in rodents since body temperature has a direct impact on cardiovascular function, drug efficacy, the pharmacokinetics of toxins and drugs, and many other effects (Gordon 2017).

For rodents underground the best way to dissipate excess heat is through conduction cooling (Pleštilová et al 2020). These animals exhibit behavior of compressing their body surface inside their dens, moving to places in tunnels 
with cooler walls. In this way, thermal conductance in underground rodents becomes relatively high and aids in cooling (Buffenstein 2000; Pleštilová et al 2020). In addition, they avoid making contact between the ventral area, which is less hairy, with low-temperature surfaces, thus minimizing cold stress (Boyles et al 2012).

\section{Autonomous processes}

The most effective way of cooling in mammals is through evaporation, although evaporation is limited in environments saturated with water vapor, which makes sweating inefficient (Baldo et al 2015; Withers et al 2016). However, thermal exchange by cutaneous evaporation is not very efficient in rodents, so other thermoregulatory mechanisms are required to dissipate excess heat (Krattenmacher and Rübsamen 1987; Baldo et al 2015; Pleštilová et al 2020). In this context, these animals are known to respond more effectively to environmental thermal variation by modulating thermogenesis via autonomic processes and thereby activating sensible heat transfer mechanisms, for heat loss or gain (Šumbera et al 2007; Gordon et al 2014; Queiroz et al 2019, 2020).
In some wild rodent species, such as African mole-rats (Fukomys mechowii and Heliophobius argenteocinereus), agoutis (Dasyprocta leporina), and Spix's yellow-toothed cavy (Galea spixii), a physiological pathway has been identified at specific regions on the body surface through which efficient heat dissipation occurs. It is known that these regions have little or no hair, in addition to having high peripheral blood circulation. Such characteristics facilitate thermal exchange with the environment, which has led to these regions being called thermal windows (Romanovsky et al 2002; Šumbera et al 2007). When studying the thermal exchanges of the Spix's yellow-toothed cavy (Galea spixii) in a semi-arid region of northeastern Brazil, Queiroz et al (2020) identified that the pinnae and vibrissae regions acted as thermal windows, described by them as the primary thermoregulatory process of these rodents in their defense against overheating. In the same region of Brazil, Queiroz et al (2019) also identified biological thermal windows in agoutis (Dasyprocta leporina). The body regions that dissipated excess heat more efficiently during the hottest times of the day were the pinnae and hind limbs.

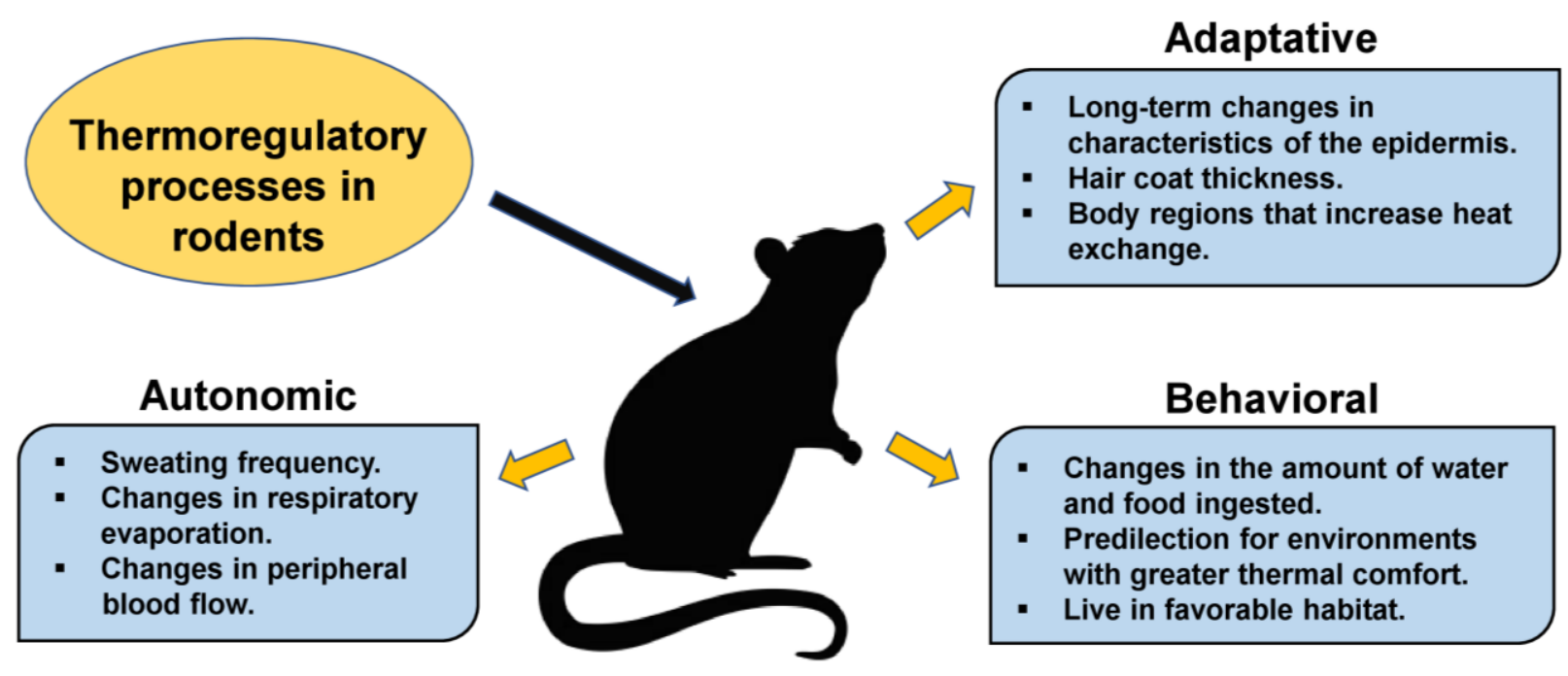

Figure 1 Schematic drawing of thermoregulatory processes in rodents.

\section{Adaptive processes}

Another thermoregulatory strategy found in rodents is related to adaptive processes. In this regard, the physiology of some of these animals is adapted for thermoregulation and survival in critical environments. For example, fossorial rodents such as the naked mole-rat Heterocephalus glaber (Bathyergidae, Rodentia) live in underground burrows with a microclimate that varies very little, which is highly advantageous in hot and arid ecosystems, as found in some regions of Africa, whose ground surface temperature is very high during the day (Šumbera 2019; Luna et al 2017 2019). While excavation is a great adaptive tool against thermal stress, there is still a risk that the body could overheat under these conditions, as the humid atmosphere of the burrow makes evaporative cooling ineffective, thereby making heat dissipation difficult (Šumbera 2019). In this context, underground rodents need efficient thermoregulatory mechanisms of caloric metabolism control, regulating the rate of gas exchange to decrease body temperature and minimizing water loss by respiratory and cutaneous evaporation (Vandewint et al 2019).

Studying another subterranean rodent, the giant mole-rat mole Fukomys mechowii (Bathyergidae, Rodentia), Pleštilová et al (2020) observed that the characteristics of the coat are probably the main means used by this species to dissipate or conserve body heat, as regions with lower hair 
density facilitated thermal changes and consequently thermoregulation. In this context, it was observed that African mole-rats (Bathyergidae) dissipate excess body heat mainly through their venter, a region in constant contact with the soil surface (Vejmělka et al 2019). In Mashona mole-rats Fukomys darlingi and Cryptomys hottentotus pretoriae, the thermoregulatory efficiency of the skin can easily be influenced by different coat patterns along the body (Boyles et al 2012). The greater the density of the hair, the greater the ability to conserve heat.

Queiroz et al (2020) studied Spix's yellow-toothed cavy (Galea spixii) in a semi-arid region of northeastern Brazil and found that they can dissipate heat using evaporation through the nose, at times of day with lower temperatures. When the upper airways are slightly warmer than the ambient temperature and humid air is inspired, body heat is dissipated by evaporation and convection, causing the temperature of the nasal surface to drop.

\section{Final Considerations}

Regardless of the thermoregulatory process used, rodents have mechanisms developed throughout the evolution of the species to confront the thermal challenges caused by the environments in which they live. In-depth study of the main thermoregulatory processes of rodents allows us to understand how these animals respond to environmental challenges and how they adapt to climate adversity.

\section{Acknowledgments}

To Capes, for funding the doctoral scholarship of the first author.

\section{Conflict of Interest}

The authors declare that there are no conflict of interest with this work.

\section{Funding}

This research did not receive any financial support.

\section{References}

Baldo MB, Antenucci CD, Luna F (2015) Effect of ambient temperature on evaporative water loss in the subterranean rodent Ctenomys talarum. Journal of Thermal Biology 53:113-118. doi: 10.1016/j.jtherbio.2015.09.002.

Bonebrake TC, Rezende EL, Bozinovic F (2020) Climate Change and Thermoregulatory Consequences of Activity Time in Mammals. The American Naturalist. doi: 10.1086/709010.

Boyles JG, Verburgt L, McKechnie AE, Bennett NC (2012) Heterothermy in two mole-rat species subjected to interacting thermoregulatory challenges. Journal of Experimental Zoology Part A: Ecological Genetics and Physiology 317:73-82. doi: 10.1002/jez.723.
Buffenstein R (2000) Ecophysiological responses of subterranean rodents to underground habitats. In: Lacey E, Patton JL, Cameron GN, eds. Life Underground: The Biology of Subterranean Rodents. Chicago: The University of Chicago Press, 62-110.

Gordon CJ (2012) The mouse: an "average" homeotherm. Journal of Thermal Biology 37:286-290.

Gordon CJ, Aydin C, Repasky EA, Kokolus KM, Dheyongera G, Johnstone AFM (2014) Behaviorally mediated, warm adaptation-a physiological strategy when mice behaviorally thermoregulate. Journal of Thermal Biology 44:4146.

Gordon CJ (2017) The mouse thermoregulatory system: Its impact on translating biomedical data to humans. Physiology \& behavior 179:55-66.

Luna F, Naya H, Naya DE (2017) Understanding evolutionary variation in basal metabolic rate: An analysis in subterranean rodents. Comparative Biochemistry and Physiology Part A 206:87-94.

Luna F, Sastre-Serra J, Oliver J, Antenucci D (2019) Thermogenic capacity in subterranean Ctenomys: Species-specific role of thermogenic mechanisms. Journal of Thermal Biology 80:64-171.

Krattenmacher R, Rübsamen K (1987) Thermoregulatory significance of nonevaporative heat loss from the tail of the coypu (Myocastor coypus) and the tammar-wallaby (Macropus eugenii). Journal of Thermal Biology 12:15-18. doi: 10.1016/0306-4565(87)90017-9.

Pleštilová L, Okrouhlík J, Burda H, Sehadová HM, Valesky E, Šumbera R (2020) Functional histology of the skin in the subterranean African giant mole-rat: thermal windows are determined solely by pelage characteristics PeerJ 8:e8883.

Queiroz JPAF, Souza Jr JBF, Oliveira VRM, Castelo TS, Dantas MRT, Costa LLM, Oliveira MF (2019) Sensible heat transfer and thermal windows in Dasyprocta leporina (Mammalia, Rodentia), Biological Rhythm Research 0:113.

Queiroz JPAF, Souza Jr JBF, Oliveira VRM, Costa LLM, Oliveira MF (2020) How does Spix's yellow-toothed cavy (Galea spixii Wagler, 1831) face the thermal challenges of the Brazilian tropical dry forest? Journal of Thermal Biology 88:102525.

Rezende EL, Bozinovic F (2019) Thermal performance across levels of biological organization. Philosophical Transactions of The Royal Society $B$ Biological Sciences 374:20180549.

Silva RG (2000) Introdução à bioclimatologia animal. São Paulo, Nobel, 286p.

Šumbera R, Zelová J, Kunc P, Knížková I, Burda H (2007) Patterns of surface temperatures in two molerats (Bathyergidae) with different social systems as revealed by IR-thermography. Physiol Behav 92:526-532.

Šumbera R (2019) Thermal biology of a strictly subterranean mammalian family, the African mole-rats (Bathyergidae, Rodentia) - a review. Journal of Thermal Biology 79:166-189.

Vandewint AL, Zhu-Pawlowsky AJ, Kirby A, Tattersall GJ, Pamenter ME (2019) Evaporative cooling and vasodilation mediate thermoregulation in naked mole-rats during normoxia but not hypoxia. Journal of Thermal Biology 84:228-235.

Vejmělka F, Okrouhlík J, Lövy, et al (2021) Heat dissipation in subterranean rodents: the role of body region and social organisation. Scientific Reports 11:2029. doi: 10.1038/s41598-021-81404-3.

Withers PC, Cooper CE, Maloney SK, Bozinovic F, Cruz-Neto AP (2016) Ecological and environmental physiology of mammals. Oxford: Oxford University Press. 